\title{
Nanotheranostics
}

2017; 1(3): 338-345. doi: 10.7150/ntno.20758

Research Paper

\section{Amplified visual immunosensor integrated with nanozyme for ultrasensitive detection of avian influenza virus}

\author{
Syed Rahin Ahmed ${ }^{1}$, Juan C. Corredor ${ }^{2}$, Éva Nagy²$^{2}$, Suresh Neethirajan ${ }^{1 凶}$ \\ 1. BioNano Laboratory, School of Engineering, University of Guelph, Guelph, Ontario, N1G 2W1, Canada \\ 2. Department of Pathobiology, Ontario Veterinary College, University of Guelph, Guelph, Ontario, N1G 2W1, Canada \\ $\bowtie$ Corresponding author: Prof. Suresh Neethirajan, Email: sneethir@uoguelph.ca (S. Neethirajan). Tel: 1.519.824.4120 Ext: 53922 \\ (C) Ivyspring International Publisher. This is an open access article distributed under the terms of the Creative Commons Attribution (CC BY-NC) license \\ (https://creativecommons.org/licenses/by-nc/4.0/). See http://ivyspring.com/terms for full terms and conditions.
}

Received: 2017.05.27; Accepted: 2017.06.17; Published: 2017.07.08

\begin{abstract}
Nanomaterial-based artificial enzymes or nanozymes exhibit superior properties such as stability, cost effectiveness and ease of preparation in comparison to conventional enzymes. However, the lower catalytic activity of nanozymes limits their sensitivity and thereby practical applications in the bioanalytical field. To overcome this drawback, herein we propose a very simple but highly sensitive, specific and low-cost dual enhanced colorimetric immunoassay for avian influenza $A$ $\left(\mathrm{H}_{5} \mathrm{NI}\right)$ virus. 3,3',5,5'- Tetramethylbenzidine (TMBZ) was used as a reducing agent to produce gold nanoparticles (Au NPs) with blue colored solution from a viral target-specific antibody-gold ion mixture at first step. The developed blue color from the sensing design was further amplified through catalytic activity of Au NPs in presence of TMBZ-hydrogen peroxide $\left(\mathrm{H}_{2} \mathrm{O}_{2}\right)$ solution in second step. Hence, the developed dual enhanced colorimetric immunosensor enables the detection of avian influenza virus $A(\mathrm{H} 5 \mathrm{NI})$ with a limit of detection (LOD) of $1.11 \mathrm{pg} / \mathrm{mL}$. Our results confirmed that the developed assay has superior sensitivity than the conventional ELISA method, plasmonic-based bioassay and commercial flu diagnostic kits. Proposed sensing method further showed its capability to detect viruses, avian influenza $A(H 4 N 6)$ and $A(H 9 N 2)$ virus, in blood samples with limit of detection of $0.0269 \mathrm{HAU}$ and $0.0331 \mathrm{HAU}$ respectively.
\end{abstract}

Key words: Dual color enhancement; Avian influenza virus detection; Gold nanoparticles; Peroxidase mimic

\section{Introduction}

Colorimetric detection of infectious virus pathogens based on specific antigen and antibody interaction enables the development of a low-cost, field-portable sensor, and has a tremendous ability to identify target analytes at an early stage in complex biological matrices [1-4]. Compared to the conventional detection techniques such as electrochemical, fluorescence or surface plasmon resonance; colorimetric visualization of diseaserelated biomarker analytes has drawn much attention recently due to its simplicity and practicality [5].

To generate significant naked-eye detectable color, natural enzymes are widely used as a labeling agent with antibodies. For example, horseradish peroxidase (HRP) and alkaline phosphatase (ALP) labeled immunoreagents are commonly used in the colorimetric immunoassay $[5,6]$ However, denaturation, low stability (temperature and $\mathrm{pH}$ ), high cost and complex purification methods hamper their use in practical field applications.

Recently, advances in nanotechnology have permitted the alternation of natural enzymes and overcome their drawbacks, i.e., the use of nanomaterials instead of natural enzymes [7-15]. Some nanomaterials are inert in biological and chemical environment and they exhibit an intrinsic enzyme mimetic activity similar to natural peroxidase [7]. So far, nanomaterial-based artificial enzymes have 
rapidly been emerging as a research interest in the nanobiotechnology field, and their applications have been extensively explored in bioanalysis, bioimaging and biomedicine [16]. Nanomaterials such as $\mathrm{Fe}_{3} \mathrm{O}_{4}$ magnetic nanoparticles (MNPs), magnetoferritin nanoparticles (M-HFn NPs), nickel nanostructure, palladium-Iridium nanoparticles (Pd-Ir NPs), platinum nanoparticles (Pt NPs), cerium oxide nanoparticles $\left(\mathrm{CeO}_{2} \mathrm{NPs}\right)$, gold nanoparticles (Au NPs), copper oxide nanoparticles (CuO NPs), carbon nanotubes and graphene possess enzyme-like activities [11,13,14,17-23]. Au NPs have frequently been used for the construction of diverse colorimetric biosensors because of their intriguing size-dependant optical properties, ease of preparation, stability and strong catalytic activities. These properties make them a promising nanomaterial for various applications using different color generating methods i.e., enzyme triggered click chemistry, alcohol dehydrogenase, and redox-mediated chromogenic reaction [22-26].

However, the catalytic activity of nanozymes is lower than that of their natural enzymes, which ultimately affects sensitivity of the analyte detection and limits their use in bioanalysis [27]. To address these challenges, efforts have begun to develop nanozymes with enhanced catalytic activities. An enzyme-cascade-amplification strategy opens a new horizon in bioassay where natural enzymes and nanozymes work together within a confined environment. This cascade reaction is catalyzed by nanozymes and results in a signal amplification of several orders of magnitude within milliseconds.

Nanohybrids that contain two or more nanomaterials in a single entity has the potential to enhance the enzymatic activities of nanozymes. The poor catalytic activities of individual nanoparticles and low dispersibility of some nanomaterials (CNTs, graphene) could partially be overcome by combining various nanomaterials into one superstructure [23]. Such nanohybrids possesses higher enzymatic activity and are suitable to develop ultra-sensitive colorimetric immunosensor.

Despite the significant progress in terms of the catalytic activity of nanozymes, cost-effectiveness due to the use of different chemicals and multistep preparation processing remains a weakness. This problem continues to impede the use of nanozymes in real-life applications. In addition, the lack of monodispersibility and uniform size of nanomaterials might be affecting the catalytic activities. Therefore, new strategies are urgently needed to design an applicable colorimetric detection system considering the aforementioned limitations.

In this study, a dual enhanced colorimetric detection system for avian influenza A (H5N1) virus was designed using lower amounts of chemicals and by avoiding a multistep synthesis process. The proposed detection strategy used an in situ synthesis of Au NPs from a target virus-specific antibody and gold ion solution using TMBZ. At this stage, a blue color was developed due to oxidization of TMBZ, which deepened in color upon addition of a TMBZ- $\mathrm{H}_{2} \mathrm{O}_{2}$ system due to the catalytic activity of synthesized $\mathrm{Au}$ NPs. The developed synthesis process does not require washing steps or the modification of the enzymatic activities of Au NPs. The change of color is directly correlated with the virus concentration, and hence enables the monitoring of color changes in naked eye to determine the presence of the target avian influenza virus in the sample. To demonstrate the practical applications of proposed amplified colorimetric immunosensor in real world applications, two low pathogenic avian influenza i.e., A (H4N6) and A (H9N2) were chosen in this study.

\section{Materials and Methods}

\section{Materials and reagents}

Gold (III) chloride trihydrate $\left(\mathrm{HAuCl}_{4} 3 \mathrm{H}_{2} \mathrm{O}\right)$, 3,3',5,5'-tetramethylbenzidine (TMB), Hydrogen peroxide $\left(\mathrm{H}_{2} \mathrm{O}_{2}\right)$, Nunc-Immuno 96-well plates were purchased from Sigma-Aldrich (St. Louis, MO, USA). The anti-influenza A (H5N1) virus hemagglutinin (HA) antibody [2B7] (ab135382, lot: GR100708-16), recombinant influenza virus A (Avian/Vietnam/ 1203/04) (H5N1) (lot: GR301823-1), anti-H9N2 (ab31674) antibody, goat anti-mouse IgG, horseradish peroxidase (HRP)-conjugated whole antibody ( $\mathrm{Ab}$ 97023, lot: GR 250300-11) and immunoassay blocking buffer (Ab 171534, lot: GR 223418-1) were purchased from Abcam, Inc. (Cambridge, UK). Recombinant influenza virus A (H1N1) (California) (CLIHA014-2; lot: $813 \mathrm{PH} 1 \mathrm{N1CA}$ ) was purchased from Cedarlane (Ontario, Canada). Influenza A (H5N2) hemagglutinin antibodies (Anti-H3N2 antibodies HA MAb, Lot: HB05AP2609), Influenza A (H7N9) hemagglutinin antibodies (Anti-H7N9 antibody HA MAb, Lot: HB05JA1903), recombinant influenza virus A (H5N2) HA1 (A/Ostrich/South Africa/A/109/ 2006)(lot: LC09AP1021), recombinant influenza virus A (H7N8) HA1 (A/Mallard/Netherlands/33/2006) (lot: LC09AP1323) and recombinant influenza virus A (H7N9) HA1 (A/Shanghai/1/2013) (lot: LC09JA2702) were purchased from Sino Biological, Inc. (Beijing, China). Anti-H4 (A/environment/Maryland/1101/ 06)(H4N6) polyclonal antibody was purchased from MyBioSource Inc., San Diago, USA. All experiments were performed using highly pure deionized (DI) water $(>18 \mathrm{M} \Omega \cdot \mathrm{cm})$. 


\section{Preparation of antibody and gold ion conjugated solution}

The bioconjugates of anti-HA H5N1 antibodies $(\mathrm{Ab} 135382)$ with gold ion $\left(\mathrm{Au}^{3+}\right)$ were prepared based on electrostatic interaction as follows: $1 \mathrm{~mL}$ (final concentration $1 \mu \mathrm{g} / \mathrm{mL}$ ) antibody solutions were prepared in phosphate-citrate buffer solution in which $5 \mathrm{mM}(60 \mu \mathrm{L}) \mathrm{HAuCl}_{4}$ solution was added and gentle stir for $30 \mathrm{~min}$ at $4500 \mathrm{rpm}$ speed (Southwest Science, NJ, USA). The, antibody-gold ion solution was loaded in Amicon Ultra centrifugal 50-kDa filter units (Millipore) for separation through high-speed centrifugation (15 min at $15000 \mathrm{rpm}$ ) using D3024 Micro-centrifuge (DEELAT, Calgary, Canada) and redispersed in phosphate-citrate buffer solution. A detailed $\mathrm{pH}$-dependent study was performed to check the stability of antibodies. We had not observed any changes in the solution color (light yellow) at room temperature for several months, indicating that the metal oxidation state $\mathrm{Au}$ (III) was unchanged. Gold ion i.e., $\mathrm{Au}(\mathrm{III})$, like other $\mathrm{d} 8$ compounds are typically low spin and have no unpaired electrons, and hence it is very stable at room temperature.

\section{Avian influenza A (H4N6) virus culture}

Low pathogenic avian influenza virus A H4N6 (Avian influenza virus A/Duck/Czech/56 (H4N6)) was propagated in 11-day-oldembryonated chicken eggs by inoculation into the allantoic cavity. Virus titer in allantoic fluid was determined at $72 \mathrm{~h}$ post-inoculation and expressed as $50 \%$ tissue culture infective dose $128 \mathrm{HAU} / 50 \mu \mathrm{L}$ [28].

\section{Avian influenza A (H9N2) virus culture}

Inactivated Avian influenza virus A H9N2 (A/Turkey/Ontario/1/66) was propagated in 10-day-old embryonated SPF chicken eggs. The egg-derived virus was inactivated with formalin (final concentration $0.02 \%$ ) for $72 \mathrm{~h}$ at $37^{\circ} \mathrm{C}$. The protein content of the inactivated virus preparation was determined using haemagglutination (HA) assay and expressed as $50 \%$ tissue culture infective dose 128 $\mathrm{HAU} / 50 \mu \mathrm{L}[29]$.

\section{Characterization of antibody specificity}

The specificity of the anti-H5N1 HA (Ab 135382) for influenza virus A/ Vietnam 1203/04/2009 (H3N2) was evaluated using the ELISA technique. Briefly, viral stocks were diluted with phosphate-buffered saline (PBS, $\mathrm{pH} 7.5$ ) to a final concentration of $1 \mu \mathrm{g} / \mathrm{mL}$ to perform ELISA. Virus solution $(100 \mu \mathrm{L})$ was then added to each well of a nonsterile polystyrene 96-well flat-bottom microtiter plate for overnight at $4^{\circ} \mathrm{C}$ to allow adsorption of the virus onto the plates. The plates were then rinsed with PBS $(\mathrm{pH}$ 7.5), and the surface pores were blocked with $100 \mu \mathrm{L}$ of immunoassay blocking buffer (Ab 171534) for $2 \mathrm{~h}$ at room temperature. After rinsing three times with PBS ( $\mathrm{pH}$ 7.5) solution, anti-H5N1 HA Ab $(1 \mu \mathrm{g} / \mathrm{mL})$, anti-H5N2 HA antibody $(1 \mu \mathrm{g} / \mathrm{mL})$ and anti-H7N9 HA antibody $(1 \mu \mathrm{g} / \mathrm{mL})(100 \mu \mathrm{l} /$ well $)$ were added to each of the wells, and the plate was incubated for $1 \mathrm{~h}$ at room temperature. After rinsed three times with PBS (pH 7.5), HRP-labelled secondary antibody was added to each well for $1 \mathrm{~h}$ at room temperature. Again rinsed with PBS buffer and TMBZ $(10 \mathrm{nM}) / \mathrm{H}_{2} \mathrm{O}_{2}(5$ $\mathrm{nM}$ ) solution were added to each wells (50 $\mu \mathrm{L} /$ well) for $30 \mathrm{~min}$. $10 \% \mathrm{H}_{2} \mathrm{SO}_{4}$ solution were added to each well $(50 \mu \mathrm{L} /$ well) to stop enzymatic reactions and the absorbance of the enzymatic product at $450 \mathrm{~nm}$ with reference wavelength of $655 \mathrm{~nm}$ was measured using a microplate reader (Cytation 5, BioTek Instruments Inc., Ontario, Canada) to quantify the interaction of the antibodies with the influenza viruses. Same procedure was followed to check the antibodies specificity for avian influenza virus A (H4N6) and A (H9N2).

\section{Colorimetric detection of avian influenza A (H5N1) virus}

Avian influenza virus A (H5N1) stock solution $(0.47 \mathrm{mg} / \mathrm{mL})$ was serially diluted with a PBS buffer ( $\mathrm{pH}$ 7.5) to create sensing subjects for this experiment. Virus solution $(100 \mu \mathrm{L})$ was then added to each 96-well plate and incubated for overnight at $4^{\circ} \mathrm{C}$. BSA $(100 \mu \mathrm{L}, 1 \mathrm{ng} / \mathrm{mL})$ was used as a negative control for testing the selectivity and specificity of the proposed sensing method. A series of different influenza viruses were used for evaluation of the specificity in this experiment. After rinsing with PBS ( $\mathrm{pH}$ 7.5) three times and being blocked with $100 \mu \mathrm{L}$ of $2 \%$ skim milk for $2 \mathrm{~h}$ at room temperature, $50 \mu \mathrm{L}$ of antibody-gold ion bioconjugates was added to the pre-adsorbed wells, and the plates were incubated for $1 \mathrm{~h}$ at room temperature. After washing three times with PBS $(\mathrm{pH}$ $7.5)$, a $50 \mu \mathrm{L}$ mixture of TMBZ $(10 \mathrm{nM})$ was added into each of the wells for the color development (bluish-green color), and intensity was further developed with the addition of $50 \mu \mathrm{L}$ TMBZ (10 $\mathrm{nM}) / \mathrm{H}_{2} \mathrm{O}_{2}(5 \mathrm{nM})$ solution within milliseconds. After $10 \mathrm{~min}, 50 \mu \mathrm{L}$ of $10 \% \mathrm{H}_{2} \mathrm{SO}_{4}$ was added to each well to stop the reaction. The absorbance at $450 \mathrm{~nm}$ was measured, and a dose-dependent curve was constructed based on the absorbance values at different concentrations of avian influenza virus. Same method was performed in case of the viral culture samples i.e., A (H9N2) and A (H4N6) determination. 


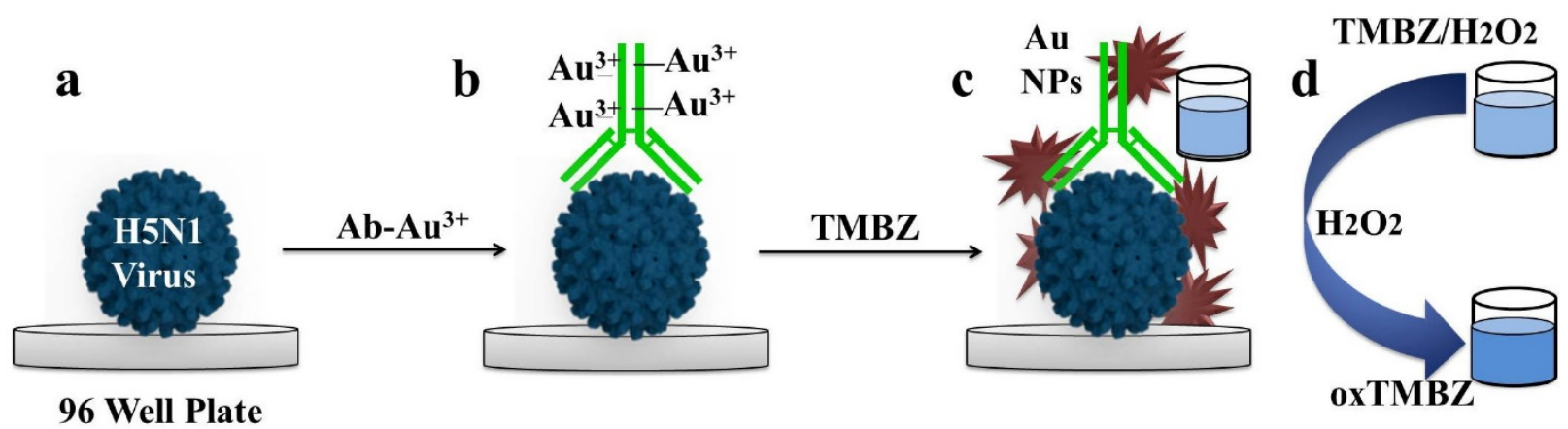

Figure 1. Schematic presentation of dual enhanced colorimetric detection. (a) Deposition of avian influenza virus on 96-well plates. (b) Target virus-specific antibody-gold ion added on virus surface. (c) Upon the addition of TMBZ, Au nanostructures form, causing development of a bluish-green color. (d) The bluish-green color becomes more intense with the addition of a TMBZ- $\mathrm{H}_{2} \mathrm{O}_{2}$ solution due to the enzymatic reaction of the Au nanostructure.

\section{Validation study with commercial ELISA kit}

A comparison study was performed with the commercial avian influenza A H5N1 ELISA kit (Cat. No: MBS9324259, MyBioSource, Inc., San Diego, USA) to validate the proposed method. Different virus titers were prepared using sample diluent provided in the ELISA kit box and by strictly following the manufacturer's protocol in the performance of the bioassay. Positive and negative avian influenza diagnostic results were obtained from different intensity of colors that appeared on the 96-well plates at room temperature.

\section{Spectroscopy and structural characterization}

Transmission electron microscopy (TEM) images were acquired using Tecnai TEM (FEI Tecnai G2 F20, Ontario, Canada). The ultraviolet-visible (UV-vis) spectrum was recorded using a Cytation 5 spectrophotometer (BioTek Instruments, Inc., Ontario, Canada). Antibody-gold ion conjugates were monitored by Fourier transform infrared spectroscopy (FT-IR spectroscopy) (FT/IR6300, JASCO Corp., Tokyo, Japan). Zeta potential was measured with Zetasizer Nano ZS (Malvern Instruments Ltd., Worcestershire, UK).

\section{Results}

\section{In situ synthesis of gold nanoparticles and their catalytic activity study}

In this study, TMBZ was chosen as a key chemical to synthesize $\mathrm{Au}$ NPs with bluish-green colored solution, as schematically depicted in Figure 1. We chose TMBZ for several reasons. Firstly, it acts as a reducing agent of gold ions and a stabilizer of $\mathrm{Au}$ NPs, forestalling the need for an extra stabilizer. Secondly, TMBZ can produce Au NPs with a positive charge (because of an $-\mathrm{NH}_{2}$ group in its chemical structure). These positively charged NPs have strong catalytic activity and color-producing ability towards the TMBZ- $\mathrm{H}_{2} \mathrm{O}_{2}$ compared to negatively charged $\mathrm{Au}$
NPs, as we reported earlier [20]. Therefore, synthesized $\mathrm{Au}$ NPs with bluish-green colored solution were further showed peroxidase-like activity and produced deeper colored solution by adding the TMBZ- $\mathrm{H}_{2} \mathrm{O}_{2}$ solution without any washing steps. Here, gold ion bonded with the antibodies through electrostatic interaction. Upon addition of the TMBZ reducing agent, the gold ions convert into elemental gold atoms, which was then formed as gold nanostructures through a bottom up process.

Before starting the sensing assay, an experiment was performed with only gold ions to check the viability of our proposed method. The results are shown in Figure 2. It was clearly observed with the naked eye that a bluish-green colored solution was developed by the reaction of gold ions and TMBZ (Step 1, Fig. 2A-a), which in turn became more intense in color with the addition of the TMBZ- $\mathrm{H}_{2} \mathrm{O}_{2}$ solution (Step 2, Fig. 2A-b). Spectroscopic study of colored solutions (Step 2) revealed an enhanced spectrum peak centered at $655 \mathrm{~nm}$ compared to Step 1. In addition, a plasmonic peak with a broader spectrum of positively charged Au NPs $(+25.6 \mathrm{eV})$ appeared at around $550 \mathrm{~nm}$ (Fig. 2B).

\section{Characterization of gold nanoparticles (Au NPs)}

In the present work, the reducing ability of TMBZ was applied to prepare gold nanostructures by reducing gold ion attached (final concentration of $\mathrm{HAuCl}_{4}$ solution was $0.01 \mathrm{mM}$ ) with specific antibodies at room temperature. A charge-transfer complex (TMBZ and $\mathrm{TMBZ}^{2+}$ ) nanofibers due to the oxidation of TMBZ was also obtained along with gold nanostructures [30]. A series of characterization was done to confirm the presence of Au nanostructure. As shown in Figure 3, a TEM image revealed several micro-length TMBZ fibers with nanoscale diameter, which were formed during the reaction (Fig. 3A). A close view of the nanofibers shows nanoscale gold particles present inside the TMBZ fibers (Fig. 3B). The 
A
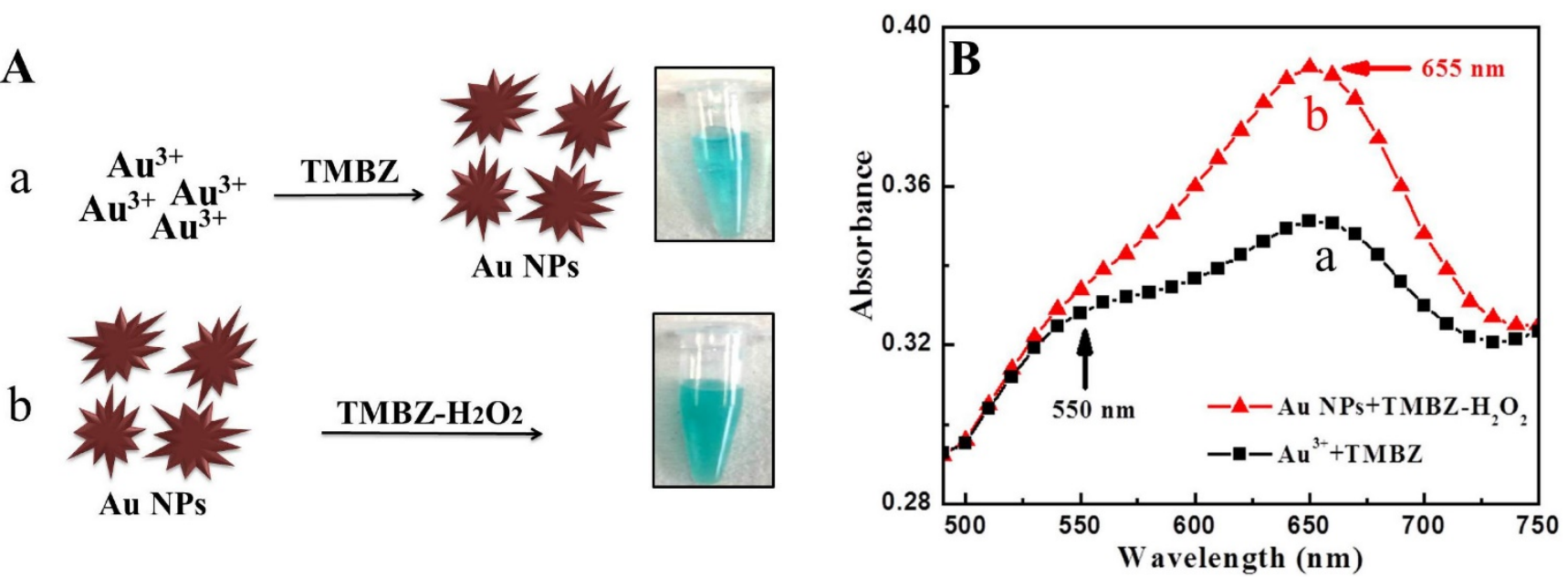

Figure 2. Viability test of proposed method. (A) The TMBZ reacted with the gold ions to form Au NPs with a bluish-green color. (a) The solution's color deepened with the addition of the TMBZ- $\mathrm{H}_{2} \mathrm{O}_{2}$ solution. (b) (Inset: naked-eye image) (B) UV-visible spectrum of Steps (a) \& (b).

diameter of the nanostructured gold was approximately $10 \mathrm{~nm}$ with a non-spherical shape and concentration was $4.6 \times 10^{-11} \mathrm{M}$ (Fig. 3C). The elementary analysis also confirmed the presence of large-scale TMBZ nanofiber and Au nanostructure (white dotted) in solution. In figure $3 \mathrm{D}$, the elementary analysis confirmed the presence of a gold nanostructure with 72.4 and 31.73 weight and atomic percentage respectively. The crystal structure of the $\mathrm{Au}$ nanostructure was characterized using X-Ray
Diffraction (XRD) analysis. The diffraction peaks appeared at $2 \theta$ values of $38.3,44.1,64.1,79.2$ and 81.6, representing (111), (200), (220), (311) and (222) planes of Au nanostructure respectively (Fig. 4A) [23]. To get the best enzymatic activity from synthesized $\mathrm{Au}$ nanostructures, several parameters were optimized. As shown in figure S1, Au nanostructure showed its best catalytic activity within $10 \mathrm{~min}$ after adding a mixture of TMBZ $(10 \mathrm{nM})$ and $\mathrm{H}_{2} \mathrm{O}_{2}(5 \mathrm{nM})$ on it.
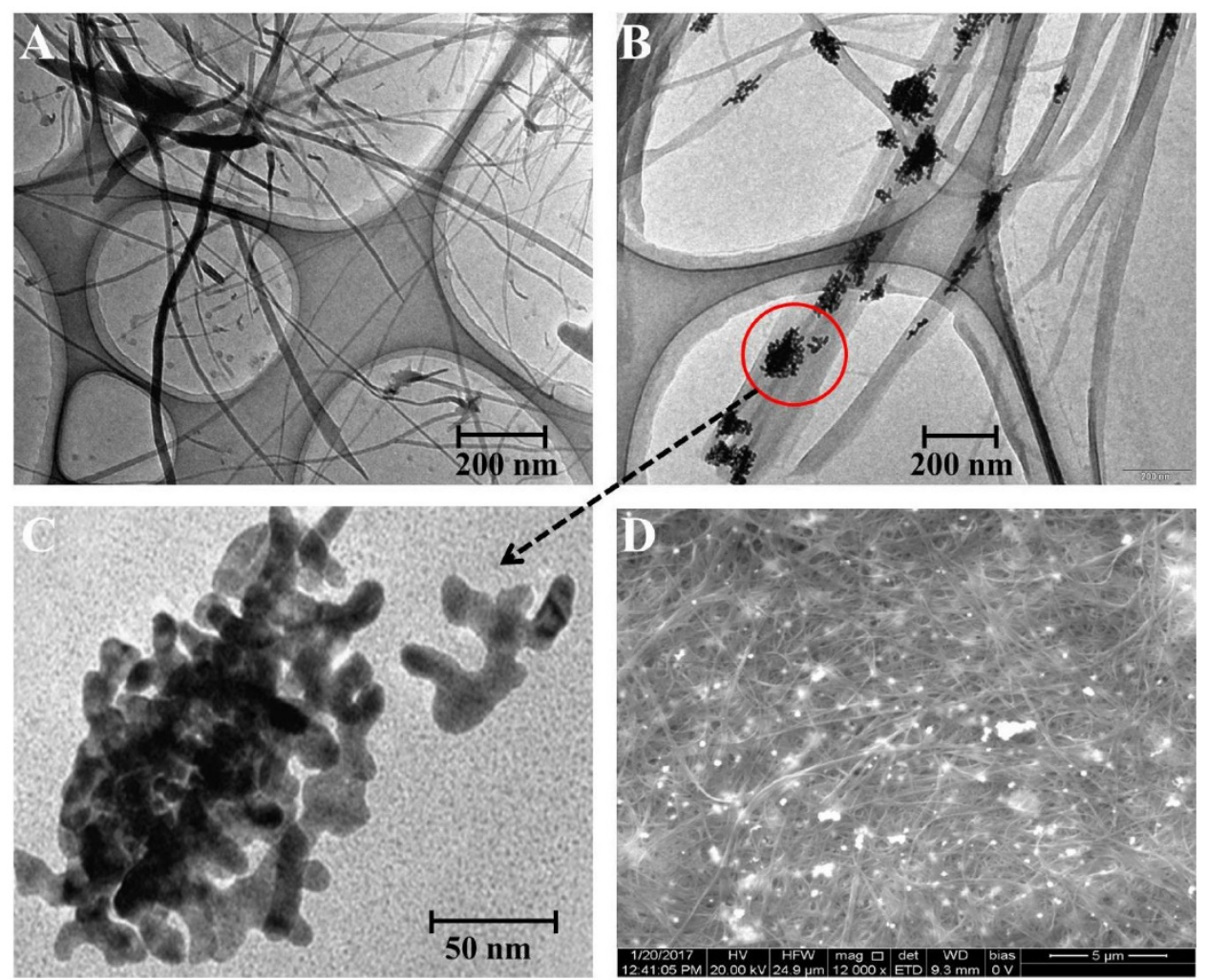

Figure 3. Microscopic study of TMBZ fiber and Au NPs. (A) TEM image of TMBZ fiber. (B) Closed view of TMBZ fiber. (C) Au nanostructure. (D) SEM image of TMBZ fiber and Au NPs. 

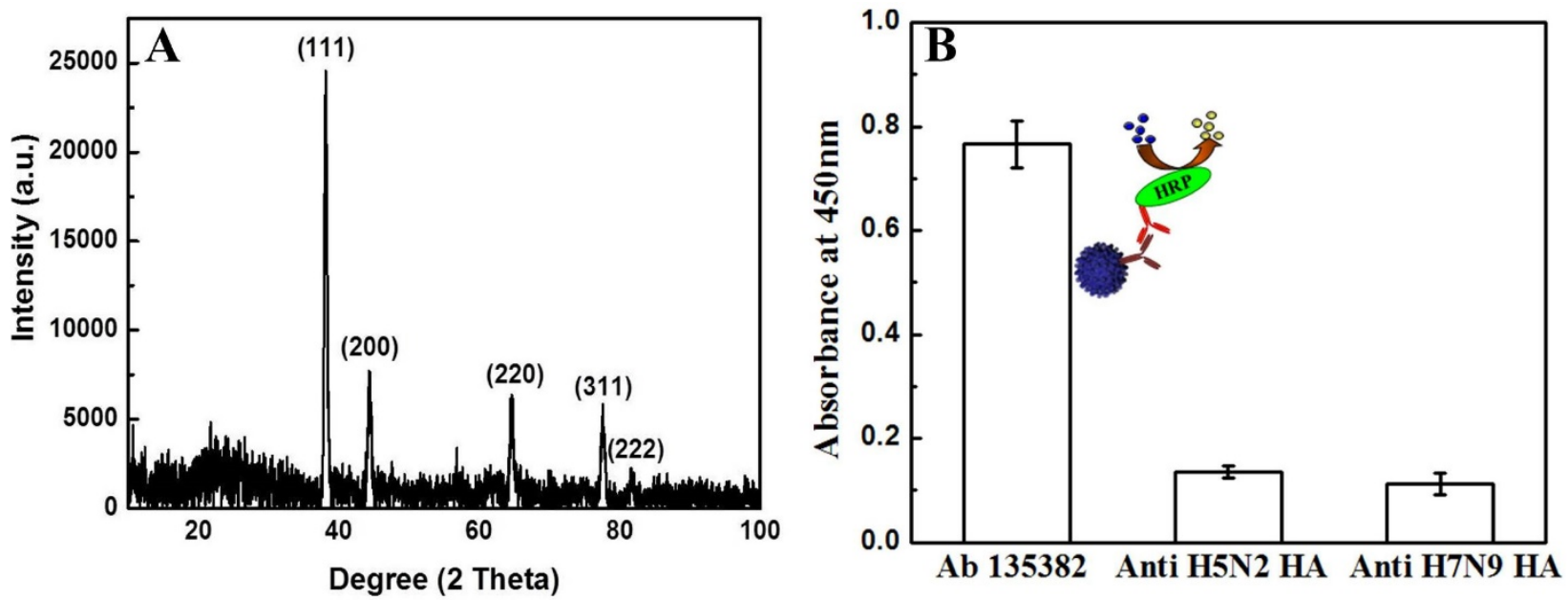

Figure 4. Optical study of Au nanostructure and antibody specificity towards target virus. (A) X-ray diffraction spectra of Au nanostructure. (B) ELISA results of antibody specificity towards target virus.

\section{Specificity of antibody towards target virus}

The specificity of anti-influenza A (H5N1) virus hemagglutinin (HA) antibody $\mathrm{Ab} 135382$ against recombinant influenza virus A (Avian/Vietnam/ 1203/04) (H5N1) was confirmed using a conventional ELISA method. Fig. 4B shows that the optical density obtained for the target virus/Ab 135382/ HRP-conjugated secondary antibody/TMBZ- $\mathrm{H}_{2} \mathrm{O}_{2}$ solution was higher than those of Anti-H5N2 HA and anti-H7N9 $\mathrm{HA} \mathrm{Ab}$, implying the specificity of $\mathrm{Ab}$ 135382 against recombinant influenza virus A (Avian/Vietnam/1203/04) (H5N1).

\section{Binding confirmation of anti-H5N1 Ab 135382 with gold ions}

The $\mathrm{pH}$ dependant stability of anti-H5N1 Ab 135382 on $\mathrm{HAuCl}_{4}$ solution and its binding results with gold ions was investigated. Here, $\mathrm{Au}^{3+}$ ions bind with negatively charged antibodies $(-1.76 \mathrm{eV})$ through electrostatic force. Antibody-to-gold ion ratios were determined using ultraviolet-visible (UV-Vis) spectroscopy. Typical ratios were kept approximately $8 \mathrm{Au}^{3+}$ ions per antibody to ensure that free sides were available for coupling with the target virus surface. The stability of antibodies in different $\mathrm{pH}$ was examined using ELISA method and showed in Figure S2. At low $\mathrm{pH} \leq 2$, irreversible precipitation of antibodies occurred and may lose their biofunction. The activities of antibodies also reduced with increasing $\mathrm{pH}$ values at alkaline media. Hence, a $\mathrm{pH}$ value of $\sim 4$ was kept during conjugation of antibodies with gold ions (Fig. S3A). The binding of antibodies and gold ions $\left(\mathrm{Ab}-\mathrm{Au}^{3+}\right)$ solution was further confirmed by FTIR analysis. In Figure S3B, two new peaks arose compared to bare antibodies and $\mathrm{HAuCl}_{4}$ in the range of 3200-3000 $\mathrm{cm}^{-1}$, indicating new bonding between antibodies and $\mathrm{HAuCl}_{4}$. Also, higher optical density obtained for $\mathrm{Ab}-\mathrm{Au}^{3+}$ solution in ELISA results further confirmed the successful binding between antibodies $(\mathrm{Ab})$ and gold ions $\left(\mathrm{Au}^{3+}\right)$ (Fig. S4).

\section{Specificity of proposed bioassay}

The catalytic activity of the proposed bioassay was investigated using four different reaction mixtures: a) recombinant influenza virus A (Avian/Vietnam/1203/04) (H5N1) / Ab135382-gold ion conjugates/TMBZ; b) replacing the specific Ab135382-gold ion conjugates with another anti-H5N2 HA-gold ion conjugate in the reaction mixture; c) removing the TMBZ from the reaction mixture and $\mathrm{d}$ ) removing the gold ions (only $\mathrm{Ab}$ 135382) from the reaction mixture (a). A deep bluish-green color developed in the sample mixture (only (a)), and a strong characteristic absorption peak at $655 \mathrm{~nm}$ was also observed (Fig. S5). However, no such characteristic peak was observed for other mixtures (b, c and d), suggesting that the proposed sensing method is highly specific and color development occurs only with the target virus, its specific Ab-conjugated gold ions and TMBZ.

\section{Quantitative analysis of avian influenza virus}

A wide range of quantitative analysis for recombinant influenza virus A (H5N1) detection was performed after confirming the specificity and binding of $\mathrm{Ab} 135382$ towards the target virus. The sensitivity of this proposed system for recombinant influenza virus A (H5N1) detection was found to be in the range from $10 \mathrm{pg} / \mathrm{mL}$ to $10 \mu \mathrm{g} / \mathrm{mL}$ with an LOD value of $1.11 \mathrm{pg} / \mathrm{mL}$. In case of conventional ELISA method, the LOD value was calculated to be 909 $\mathrm{pg} / \mathrm{mL}$, suggesting that the proposed method was 811 times more sensitive than the conventional ELISA method (Fig. 5A \& Fig. S6). 

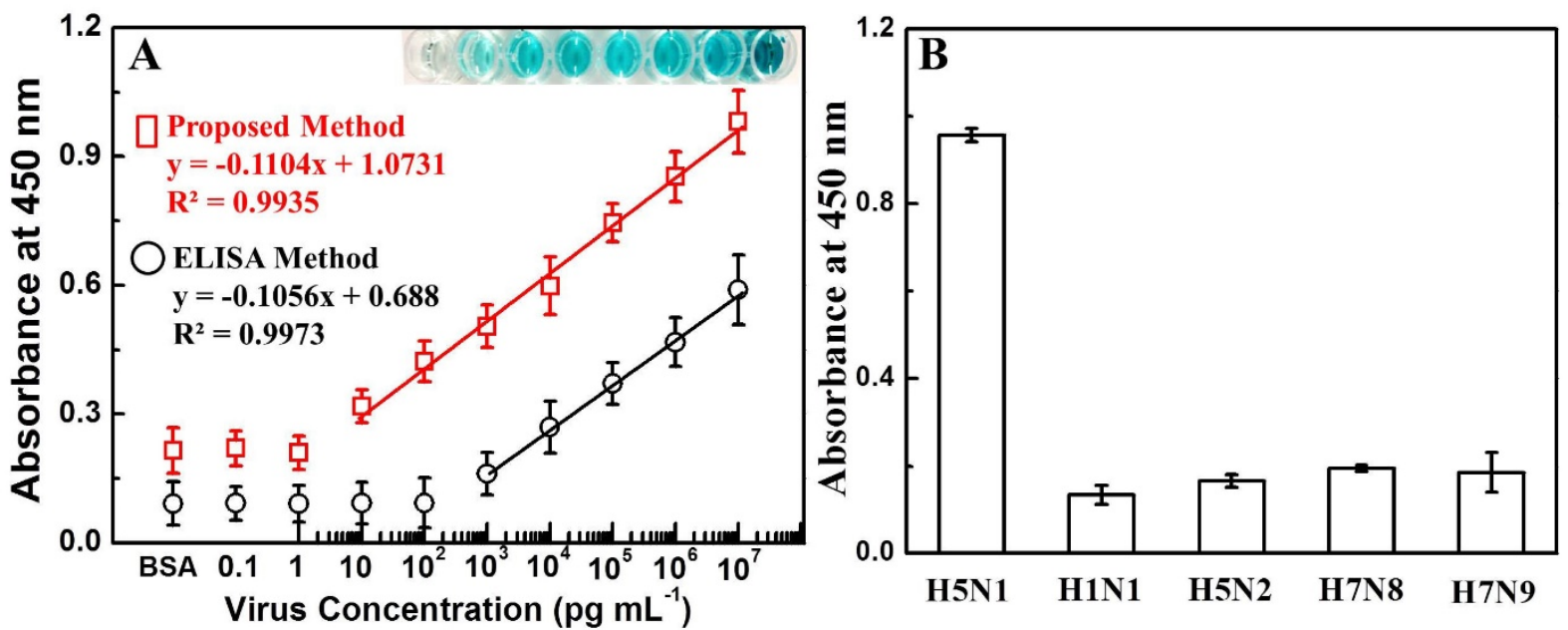

Figure 5. Detection of avian influenza virus $A(H 5 N 1)$. (A) The calibration curve of the absorbance corresponding to the concentration of avian influenza virus $A$ $(\mathrm{H} 5 \mathrm{~N} 1)$. BSA was used as a negative control. Inset: visual image of virus detection before adding $\mathrm{H}_{2} \mathrm{SO}_{4}$. Squares (red line) and circles (black line) denote proposed and conventional ELISA sensing results, respectively. (B) ELISA results for selectivity of the present study with different influenza viruses. Error bars in (A) and (B) denote standard deviations $(n=3)$.

It is instructive to do a comparative study with other nanotechnology-based analytical techniques. To do that, we have compared the present technique with the plasmonic resonance peak response of synthesized Au NPs (at the intermediate stage) with different concentrations of target analytes. As shown in Figure S7, the change of plasmonic peak located at $550 \mathrm{~nm}$ was not consistent compared to the peak at $655 \mathrm{~nm}$ (present study) and showed 10 times less sensitivity $(100 \mathrm{pg} / \mathrm{mL})$ than the current detection technique.

To evaluate the selectivity for the detection of avian influenza virus, the proposed bioassay was implemented with other virus strains, namely H1N1, H5N2, H7N8 and H7N9. As shown in Fig. 5B, a significant change in the absorbance density (8 9-fold higher) was observed with the target avian influenza virus A (H5N1) in comparison to other viruses, revealing that the developed dual enhanced immunoassay was sufficiently selective for the detection of target avian influenza virus A (H5N1).

\section{Comparison study of detection with commercial kit}

The sensitivity of the proposed method was compared with those of a commercially available avian influenza A (H5N1) diagnostic kit (Table 1, Fig. S8). The naked-eye color response to the detection of avian influenza A (H5N1) in the commercial kit was as high as $1 \mathrm{ng} / \mathrm{mL}$, indicating that our system is more sensitive than the commercial kit. Thus, the dual enhanced colorimetric technique presented here for visual detection of avian influenza viruses could be applicable for low-cost, visible, point-of-care diagnosis and also extendable to develop other nanozyme-based biomarker detection.
Table 1: Comparison of avian influenza virus $A$ (Avian/Vietnam/1203/04) (H5N1) detection using different methods

\begin{tabular}{|c|c|c|c|c|c|c|c|c|c|}
\hline \multirow[t]{2}{*}{ Detection method } & \multicolumn{9}{|c|}{ Virus concentration $(\mathrm{pg} / \mathrm{mL})$} \\
\hline & $10^{7}$ & $10^{6}$ & $10^{5}$ & $10^{4}$ & $10^{3}$ & $10^{2}$ & 10 & 1 & 0 \\
\hline This study & + & + & + & + & + & + & + & - & - \\
\hline Plasmonic assay & + & + & + & + & + & + & - & - & - \\
\hline $\begin{array}{l}\text { Conventional } \\
\text { ELISA }\end{array}$ & + & + & + & + & + & - & - & - & - \\
\hline Commercial kit & + & + & + & + & + & - & - & - & - \\
\hline
\end{tabular}

${ }^{*}$ Note: + and - denote positive and negative diagnoses, respectively.

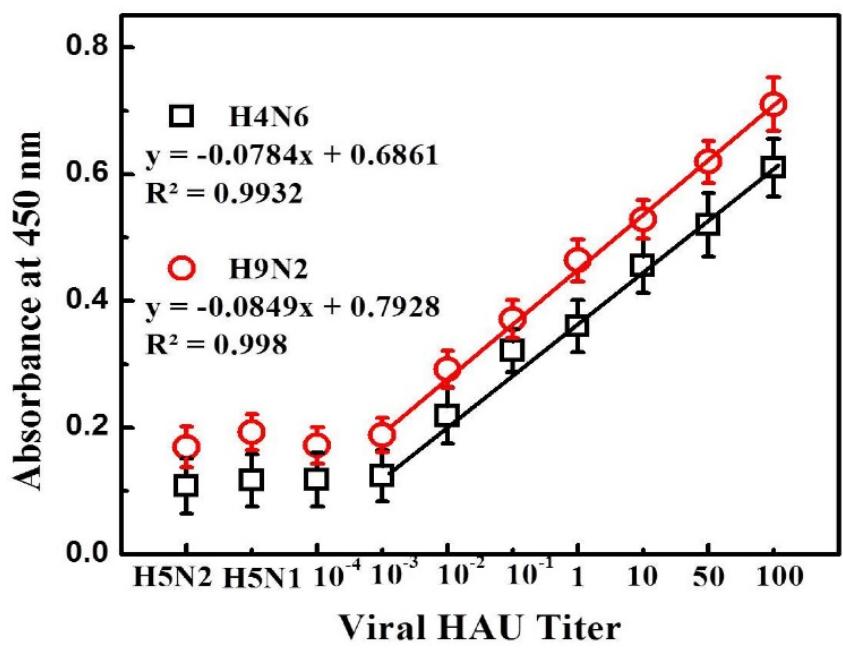

Figure 6. Detection of avian influenza virus $A(H 4 N 6)$ and $A(H 9 N 2)$ in blood sample. Here, viral titer was expressed as $\mathrm{HAU} / 50 \mu \mathrm{L}$. H5NI and $\mathrm{H} 5 \mathrm{~N} 1$ virus was used as a negative control. Error bars denote standard deviations $(n=3)$.

We also explored the practical application of the developed assay in blood samples with avian influenza A (H4N6) and A (H9N2) virus detection that represent a complex biological mixture. After confirmed the specificity of antibodies towards 
viruses (Fig. S9), a calibration curve for colorimetric detection was obtained by the standard dilution method (Figure 6). A linear range of detection for both avian influenza A (H4N6) and A (H9N2) virus in blood was found to be from 100 to $0.01 \mathrm{HAU}$ with limit of detection 0.0269 HAU and 0.0331 HAU respectively calculated by standard deviation method. Thus, the proposed amplified colorimetric immunosensor showed its detection ability even at complex media.

\section{Conclusions}

A facile design of enhanced colorimetric detection for avian influenza virus was developed in this study. A remarkable improvement of the color visualization, as well as detection sensitivity, was observed due to the dual effects of the sensing mechanism. The blue colour developed during the Au NPs synthesis process was further amplified due to the peroxidase-like activity of Au NPs in the presence of a TMBZ- $\mathrm{H}_{2} \mathrm{O}_{2}$ mixture. Our study not only provides a facile synthetic route for Au NPs but also opens an innovative approach for biosensor development using $\mathrm{Au}$ NPs as nanozymes. Experiments results revealed that the proposed method has capability to detect commercial avian influenza virus A (H5N1) HA protein with a limit of detection (LOD) of $1.11 \mathrm{pg} / \mathrm{mL}$. While applied the same method for avian influenza A (H4N6) and A (H9N2) virus detection in blood sample, the limit of detection was observed 0.0269 HAU and 0.0331 HAU respectively. Thus, the proposed bioassay is applicable in practical field.

\section{Supplementary Material}

Supplementary figures.

http://www.ntno.org/v01p0338s1.pdf

\section{Acknowledgements}

The authors sincerely thank the Natural Sciences and Engineering Research Council of Canada (400929), Ontario Ministry of Agriculture, Food and Rural Affairs (298634), Canadian Poultry Research Council (300142) and the Egg Farmers of Canada (201928) for funding this study.

\section{Author Contributions}

SA designed the research, synthesized and characterized the nanomaterials. SN conceptualized and initiated the project. SA performed the experiments. SA wrote the manuscript with SN.

\section{Competing Interests}

The authors have declared that no competing interest exists.

\section{References}

1. Xu S, Ouyang W, Xie P et al. Highly uniform gold nanobipyramids for ultrasensitive colorimetric detection of influenza virus. Anal Chem. 2017; 89: $1617-1623$.

2. Rakow NA and Suslick KS. A colorimetric sensor array for odour visualization. Nature. 2000; 406: 710-713.

3. Song $\mathrm{Y}$, Wei $\mathrm{W}$ and $\mathrm{Qu} \mathrm{X}$. Colorimetric biosensing using smart materials. Adv Mat. 2011; 23: 4215-4236.

4. Ye $\mathrm{X}$, Shi $\mathrm{H}, \mathrm{He} \mathrm{X}$, et al. Iodide-responsive $\mathrm{Cu}-\mathrm{Au}$ nanoparticle-based colorimetric platform for ultrasensitive detection of target cancer cells. Anal Chem. 2015; 87: 7141-7147.

5. Gao Z, Hou L, Xu M and Tang D. Enhanced colorimetric immunoassay accompanying with enzyme cascade amplification strategy for ultrasensitive detection of low-abundance protein. Sci Rep. 2014; 4: 3966.

6. Malashikhina N, Garai-Ibabe G and Pavlov V. Unconventional application of conventional enzymatic substrate: first fluorogenic immunoassay based on enzymatic formation of quantum dots. Anal Chem. 2013; 85:6866-6870.

7. Wei $\mathrm{H}$ and Wang EK. Fe3O4 magnetic nanoparticles as peroxidase mimetics and their applications in $\mathrm{H} 2 \mathrm{O} 2$ and glucose detection. Anal Chem. 2008; 80: 2250-2254.

8. Wang X, Guo W, Hu Y, et al. Nanozymes: Next Wave of Artificial Enzymes. Springer. 2016.

9. Cheng $\mathrm{H}$, Zhang $\mathrm{L}, \mathrm{He} \mathrm{J}$, et al. Integrated nanozymes with nanoscale proximity for in vivo neurochemical monitoring in living brains. Anal Chem. 2016; 1: 1336-1343.

10. Wang $\mathrm{X}, \mathrm{Hu} \mathrm{Y}$ and Wei $\mathrm{H}$. Nanozymes in bionanotechnology: from sensing to therapeutics and beyond. Inorg Chem Front. 2016; 3: 41-60.

11. Fan K, Cao C, Pan Y, et al. Magnetoferritin nanoparticles for targeting and visualizing tumour tissues. Nat Nanotechnol.Volume: 2012; 7: 459-464.

12. Nie D, Shi G and Yu Y. Fe3O4 magnetic nanoparticles as peroxidase mimetics used in colorimetric determination of 2,4-Dinitrotoluene. Chinese J Anal Chem. 2016; 44: 179-185.

13. Wang $\mathrm{X}, \mathrm{Cao} \mathrm{W}$, Qin $\mathrm{L}$, et al. Boosting the peroxidase-like activity of nanostructured nickel by inducing its $3+$ oxidation state in $\mathrm{LiNiO} 3$ perovskite and its application for biomedical assays. Theranostics. 2017; 7(8): 2277-2286.

14. Ye H, Yang K, Tao J, et al. An enzyme-free signal amplification technique for ultrasensitive colorimetric assay of disease biomarkers. ACS Nano. 2017; 11: 2052-2059.

15. Duan D, Fan K, Dexi Zhang D, et al. Nanozyme-strip for rapid local diagnosis of Ebola. Biosens Bioelectron. 2015; 74: 134-141.

16. Wei $\mathrm{H}$ and Wang E. Nanomaterials with enzyme-like characteristics (nanozymes): Next-generation artificial enzymes. Chem Soc Rev. 2013; 42: 6060-6093.

17. Gao L, Zhuang J, Nie L, et al. Intrinsic peroxidase-like activity of ferromagnetic nanoparticles. Nat Nanotech. 2007; 2: 577-583.

18. Polsky R, Gill R, Kaganovsky L and Willner I. Nucleic acid-functionalized Pt nanoparticles: catalytic labels for the amplified electrochemical detection of biomolecules. Anal Chem. 2006; 78: 2268-71.

19. Asati A, Santra S, Kaittanis C, et al. Oxidase-like activity of polymer-coated cerium oxide nanoparticles. Angew Chem. Intl Edit. 2009; 48: 2308-2312.

20. Ahmed SR, Kim J, Suzuki T, et al. Detection of influenza virus using peroxidase-mimic of gold nanoparticles. Biotech Bioengg. 2016; 113: 2298-2303.

21. Chen W, Chen J, Feng YB, et al. Peroxidase-like activity of water-soluble cupric oxide nanoparticles and its analytical application for detection of hydrogen peroxide and glucose. Analyst. 2012; 37: 1706-1712.

22. Ahmed SR, Kim J, Suzuki T, et al. Enhanced catalytic activity of gold nanoparticle-carbon nanotube hybrids for influenza virus detection. Biosens Bioelectron. 2016; 85: 503-508.

23. Ahmed SR, Takemeura K, Li TC, et al. Size-controlled preparation of peroxidase-like graphene-gold nanoparticle hybrids for the visible detection of norovirus-like particles. Biosens Bioelectron. 2017; 87: 558-565.

24. Xianyu $Y$, Wang Z and Jiang X. A Plasmonic nanosensor for immunoassay via enzyme-triggered click chemistry. ACS Nano. 2014; 8: 12741-12747.

25. Peng MP, Ma W and Long YT. Alcohol dehydrogenase-catalyzed gold nanoparticle seed-mediated growth allows reliable detection of disease biomarkers with the naked eye. Anal. Chem. 2015; 87 (12): 5891-5896.

26. Yu RJ, Ma W, Peng MP, et al. A redox-mediated chromogenic reaction and application in immunoassay. Anal Chim Acta. 2016; 934: 226-230.

27. Cheng $\mathrm{H}$, Zhang $\mathrm{L}, \mathrm{He} \mathrm{J}$, et al. Integrated nanozymes with nanoscale proximity for in vivo neurochemical monitoring in living brains. Anal Chem. 2016; 88: 5489-5497.

28. Paul MS, Barjesteh N, Brisbin JT, et al. Effects of Ligands for Toll-Like Receptors 3, 4, and 21 as Adjuvants on the Immunogenicity of an Avian Influenza Vaccine in Chickens. Viral Immunol. 2014, 27(4): 167-173.

29. Singh SM, Alkie TN, Abdelaziz KT, et al. Characterization of immune responses to an inactivated avian influenza virus vaccine adjuvanted with nanoparticles containing CpG ODN. Viral Immunol. 2016; 29(5): 269-275.

30. Yang J, Wang $\mathrm{H}$ and Zhang $\mathrm{H}$. One-pot synthesis of silver nanoplates and charge-transfer complex nanofibers. J Phys Chem C. 2008; 112: 13065-13069. 